\begin{tabular}{|c|c|c|c|}
\hline & $\begin{array}{l}\text { Escola Superior } \\
\text { de Cestsooe } \\
\text { Techologia } \\
\text { [iPSantarém] }\end{array}$ & 颐 & $\begin{array}{l}\text { ISSN 2029-7564 (online) } \\
\text { SOCIALINÉS TECHNOLOGIJOS } \\
\text { SOCIAL TECHNOLOGIES } \\
2014,4(1) \text {, p. } 151-167\end{array}$ \\
\hline
\end{tabular}

\title{
INTELLECTUAL PROPERTY PROTECTION FOR BRAND JAMAICA'S CREATIVE INDUSTRIES
}

\author{
Keisha LaRaine Ingram \\ Mykolas Romeris University, Lithuania, kereoca@gmail.com \\ doi:10.13165/ST-14-4-1-10
}

\begin{abstract}
Since the last decade, strategies employed by governments to manage their country brands have evolved beyond tourism marketing techniques. It is quite common now for most governments to hire marketing specialists to design and implement county brand campaigns and policies to promote country brands globally to attract foreign direct investment into that country. Whether it is the arts-based "creative industry" or an "enterprise culture", these features have evolved to become the drivers of profit in global markets, and give each nation a "competitive edge" over other nations with regard to their national brand. Country brand management is integral for the successful development of industry sectors and is also dependent on good country image. For Brand Jamaica one such industry is the creative industries sector. Brand Jamaica's creative industries are mostly comprised of branded tourism accommodations, atmosphere, heritage and culture as well as the indigenous music and recordings of local artists and singers. For the development of this sector which currently contributes to Jamaica's GDP it is interpreted that enforced intellectual property will play a key role especially in promoting of the brand online. Good management of country brand creative industries involves good business acumen on protecting and developing that sector, as it is vital towards translating the intangible wealth of developing countries into economic growth. Enforced intellectual property protection for Brand Jamaica's music, arts, theatrical productions and creative expressions ultimately lessen the occurrence of infringements of the brand's assets, piracy and production of counterfeit goods and services, while creating future possibilities in cyberspace.
\end{abstract}


Purpose - as a source of unlimited supply of intellectual property, Brand Jamaica requires formal management of those assets especially in the creative industries sector that the brand is globally known for. This research seeks to uncover the extent to which intellectual property protection is important for the social and economic development of Brand Jamaica's creative industries.

Design/methodology/approach - first, it presents a theoretical analysis of scientific literature and monographs on good country brand management and country brand property, as well as the objects of intellectual property that are applicable to good country brand management pursuant to the research. Secondly, the official web page of the World Intellectual Property Office comprising many articles regarding the Economics of Intellectual Property was referenced for this research. New data from survey questionnaires are presented and will test the hypotheses raised. The hypotheses raised explore the influencers that create value for country brands with strong intellectual property rights legislation. From that perception, two hypotheses are made:

H1: Trademarks, industrial designs, copyrights and other objects of intellectual property protect Brand Jamaica.

H2: Trademarks, industrial designs, copyrights and other objects of intellectual property protection create value for Brand Jamaica.

Findings - enforced intellectual property rights indeed create possibilities for country brands, such as Brand Jamaica. This protection is enormous, especially in cyberspace as a branded e-commerce website portal. A branded website portal is ideal for online forums and building brand awareness necessary for its promotion. The findings further indicate that there is a direct relationship between country brand value and intellectual property protection.

Research Limitations/ Implications - current intellectual property protection is not actively enforced for Brand Jamaica since the right to copyright and trademark the brand by its governing state Jamaica, are withheld by the Paris Convention; as a result the resources needed to protect brand Jamaica against infringement are absent, and consequently the exploitation of the brand's intellectual property continues.

Practical Implications - strong intellectual property protection that generates equity for country brands is the main implication, although the extent to which Brand Jamaica is managed cannot be compared with other country brands of developed countries, where country brand management is undertaken at the national level.

Originality/Value - the work is useful for developing countries' country brand managers faced with the task of marketing country brands without enforced intellectual property legislation and assessing those country brands in order to manage them effectively.

Keywords: Intellectual property, brand equity, country brand, Brand Jamaica, creative industries.

Research Type: Research paper, case study, opinion view. 


\section{Introduction}

Trade in high technology goods and services, which are knowledge-intensive, and where IP protection is common, tends to be among the fastest growing in international trade. In developed countries, where intellectual property laws are enforced, there is good evidence that intellectual property requires protection for stimulating innovation in the creative industries of those sectors. However, the evidence as to the exact level of its importance in other business sectors is mixed. Developing countries of the Caribbean are renowned for the vast amount of intangible and tangible property, such as music, sports, tourism, culture, entertainment, beaches and sunny climate, all of which are marketed internationally to attract consumers. While those properties are a source of pride for the region, enforced intellectual property administration is outstanding and is required to protect and promote the IP assets of the Caribbean states. As a result of this, the region is viewed as laid back with a carefree atmosphere, although challenges concerning enforced intellectual property administration are accumulating. In 2002, when the Jamaica Intellectual Property Office (JIPO) was formed, total consolidation of laws regarding the administration of Jamaica's intellectual property was undertaken. The office became the primary institution responsible for administering intellectual property rights in Jamaica, establishing protection for creative works and managing intellectual property of Jamaican inventors, and protecting the country's national brand, Brand Jamaica. It is desired through this office that enforced IPR administration for Brand Jamaica' creative industries will stimulate national economic growth and development as well as achieve more equity for the brand.

The main themes of the research that are referenced from works of qualified research scientists and consultants already suggest that good country brands are consistent with the improvement of their image, management of their intangible and tangible assets - intellectual property, image and equity (Anholt; 2011, Fetscherin; 2010). Therefore, this research represents the analysis of the social value that intellectual property protection creates for Brand Jamaica and its creative industries.

\section{Theoretical overview of intellectual property and country brand management}

\subsection{Intellectual property}

In a very broad sense, intellectual property means the legal rights that result from an intellectual activity in the industrial, scientific, literary and artistic fields. Countries have laws to protect intellectual property for two main reasons. First, to give statutory expression of the creator's moral and economic rights to their works and the right of the public to access those works (WIPO 489e p.2; 2008). Second to promote, as a deliberate act of government policy, the creativity, dissemination and application of its results; and to encourage fair trading which contributes to economic and social development (WIPO 489e p.2; 2008). Generally speaking, intellectual property laws are aimed at safeguarding creators and producers of intellectual goods and services by 
granting time-limited rights to control the use of those productions (WIPO 489e p.2; 2008). Those rights do not apply to the physical object in which the creation may be embodied but instead to the intellectual creation. Intellectual property is traditionally divided into two branches, "industrial property" and "copyright" (WIPO 489e p.2; 2008). The object of intellectual property protection is to protect original works that are man-made, fixed or recorded. Therefore, in order to gain protection for works that are intellectually created, the work must be original and man-made. If created works are created solely by a machine then it is not susceptible to legal protection, even if the user of the machine has put original work into the machine (WIPO $489 e$ p.2; 2008). Similarly, works "created" by an animal cannot be legally protected because the inventor or originator should be a natural person. However, intellectual property rights can be gained by legal entities, such as corporations, institution or enterprises. Works that are subject to intellectual property rights protection should be fixed or recorded in some way and exclude unrecorded conversations or speeches. Intellectual property rights come into existence only when works have been created, since it is an automatic right (WIPO 489e p.3; 2008). In regards to this, the Berne Convention usually does not require that one or more copies of the work be registered or deposited as a precondition for obtaining legal rights. However, this requirement is a requisite found in the Universal Copyright Convention, and applies to the use of the copyright sign (WIPO 489e p.3; 2008).

\subsection{Promoting and protecting intellectual property}

All aspects of intellectual property should be promoted and protected. There are many studies supporting this concept, as intellectual property preserves and stimulates the well-being and progress of humanity especially for new creations in the areas of technology and culture. The legal protection of these new creations encourages the expenditure of additional resources, which leads to further innovation. Intellectual property also spurs economic growth, creates new jobs and industries, and enhances the quality and enjoyment of life when it is protected and promoted. Intellectual property rights reward creativity and human endeavour, which also fuels innovation. Intellectual property rights ensure that the creator, or the owner, of a patent, trademark, or copyright benefits from their own work or investment (WIPO 489e p.3; 2008). These rights ensure benefit from the protection of moral and material interests resulting from authorship of any scientific, literary, or artistic production. The importance of intellectual property protection was first recognised in the Paris Convention for the Protection of Industrial Property in 1883 and the Berne Convention for the Protection of Literary and Artistic Works in 1886. The World Intellectual Property Organization (WIPO) currently administers and oversees both treaties (WIPO 489e p.3; 2008).

\section{Country brand management}

\subsection{Nation branding}

The terminologies of country branding or nation branding have emerged from traditional marketing literature. Both are used interchangeably and are reinforced and 
correlated deeply in four main marketing fields: country of origin, destination branding, country-product image and country identity. Over the years, country branding has evolved and expanded beyond marketing and branding fields and has grown to include other disciplines, such as international relations and public diplomacy (Anholt; 2011). Although still in early stages, a number of academics and practitioners, such as Kotler and Anholt were among the first to discuss country branding and a number of articles were dedicated to the topic. However, there is still no universal definition for the term 'country brand' (Grosse; 2005). According to Kotler, "country brand is defined as "a country's whole image, covering political, economic, historical and cultural dimensions" (Kotler; 2005). The concept is at the national level, multidimensional and context-dependent." At the same time, Dinnie defines country brand as "the unique, multi-dimensional blend of elements that provide the nation with culturally grounded differentiation and relevance for all of its target audiences" (Grosse; 2005). Dinnie further states that country branding is a real world activity comprised of multiple levels, dimensions, and disciplines that are beyond conventional branding techniques and usually involve politicised aspects that generate international controversy as well as conflicting viewpoints and opinions (Yan; 2011). Developing successful country brands can be complex and difficult, yet it can be beneficial for the country as the results will have positive and permanent effects. It is perceived that successful country brands foster national pride, encourage productivity, enrichment, and social improvement to the citizens of the country while providing consumers with trust and personal security, and credibility for the country's citizens, improvement in tourism, increase in export revenue, trading advantages to the country itself (Yan; 2011). Country branding has become an essential part of a country's sustainable development. A strong country brand helps increase exports, attract tourism, investment, and immigration (migrants to the country). Country of origin normally influences consumer attitudes toward products originating from particular countries in multinational markets. Products sourced from industrialised countries generally tend to have favourable associations, and hence tend to be evaluated favourably, compared to those from the developing countries. Country images or associations have been mostly shown to operate as a summary construct that influences consumer product-specific beliefs and directly affects their attitudes, particularly when consumers are familiar with the products from a country. A country can have positive (or negative) country equity, if consumers react more (or less) favourably to products originating from a particular country, than they would to the product without the country name. Overall, because of its positive associations, a country name of high equity can have a positive effect on a consumer's product evaluations at the individual level and on the brand sales at the market level. As country names also work similarly to brand popularity, it is expected that short-term marketing actions by a brand possessing high country image will be more effective than that of low country image. Empirical evidence further suggests that products from high or favourable countries would charge premium prices for their favourable or unique image associations. This lends support to the view that consumers do not seem to be sensitive to premium prices. If a country name creates a unique value or image, then consumers will place greater value on any unique attributes that differentiate it from competing products and, as a result, buyers will be less sensitive 
to price premiums. At the same time, for those products emerging from developing or unfavourable countries, consumers would place more emphasis on functional or economic values, such as price deals rather than image associations, supporting the view that price sensitivity for products from unfavourable or low quality image countries would be high at the aggregate level (Kapferer; 2008).

\subsection{Country brand measurement}

This method is based on two universal methods adopted from traditional corporate branding methods. These two methods are: consumer-based brand equity approach and company-based brand equity approach and are discussed extensively (Atilgan et al; 2005) (Fetcherin; 2010). According to Atilgan, the consumer-based brand equity approach places major emphasis on the associated meanings and the value of the brand to consumers, with the brand's value determined by consumers. Although the methodology involves collecting primary survey data, the assessment of brand value is based on a bottom-up approach. At the same time, the companybased brand equity approach measures brand value using a top-down approach of measurement from the information gained on the total performance of a company. It is suggested that the same approach can be applied to a country's brand, by estimating how well the country performs in terms of exports, attracting tourism, and attracting FDIs, as well as immigration (Fetcherin; 2010).

\subsection{Country brand strength index}

The country brand strength index is an assessment of the strength of a country brand using different models and how a country is regarded by other countries. In determining the factors that constitute strong (good) country brands, Fetscherin applied a company-based brand equity approach model to develop his Country Brand Strength Index (CBSI) model. The CBSI model has a more complex methodology than that of the Nation Brand Index (NBI), because it encompasses three tiers of brands research. This index is also the first of its kind to operationalise the strength of a country brand through objective secondary data that represents an alternative measurement to the existing subjective survey-based measurement indexes that are traditionally used. Fetscherin states that the index was developed based on studies by Shimp et al., (1993); Anholt, (1998); Cho and Shu, (2006). However, Fetscherin acknowledges that country branding is unusually complex and the CBSI do not account for all dimensions of country branding phenomena, but still can be used as an alternative approach for conducting the methodology based on objective secondary data which should provide more meaningful results. Currently, traditional country brand strength measures that assess country brands derive from private sources rather than from academic literature.

Two other popular kinds that are used by country brand managers are the country brand index from FutureBrand consultancy and the Anholt GfK Roper Nation Brand Index (NBI). The Anholt-GfK Roper Nation Brands Index is a leader in brand hierarchies used in literature to measure and assess country brand strengths. 
The index is usually compiled on an annual basis and measures the efficiency with which countries construct, develop and sustain their country brands. Although quite useful and standard for many country branding projects worldwide, Fetscherin criticizes both models as he views the methodologies used as limiting and too exclusive especially in regards to the type of the questions asked, the aggregation and statistical method used, and the subjective nature and perceptions of the survey data. The results from the proposed model indicate that countries with the strongest country brand are smaller, developed European countries, and also leads to the results similar to the widely-used Anholt GfK Roper nation brand index (NBI), which measures country brand from subjective survey data. From those models it is assumed that countries that are perceived positively (based on NBI model) have a stronger country brand (CBSI model) and countries that are perceived negatively (based on the NBI) have a weak country brand (CBSI). The CBSI assesses each model on a polarity scale, even though correlated, and measures the same phenomena, using different approaches, methodologies, and data, which suggests that both complement each other and are inter-dependent. Fetscherin further maintains that in order to stay competitive in the global economy, countries need to understand how to assess their country brand in order to manage it. Fetscherin believes that through the CBSI model a country will be more able to develop a powerful country brand strategy.

Proper assessment of a country's brand requires using one or more of the models discussed, with the FutureBrand and the Anholt Brand Index models as the ones widely used by country brand managers. Moreover, a nation's brand is usually desired to encompass all the favourable aspects of the country as well as the positive images it commands in the world. When a country's national brand is highly regarded internationally, the inbound attractiveness to foreigners concerning investment, tourism, and living conditions (emigration) increases, and outbound reception of that country also increases in the form of more exports and attracting talented labour resources towards that country.

\section{Brand Jamaica: IP protection for its creative industries}

\subsection{Brand Jamaica}

Brand Jamaica constitutes both the intangible and tangible property of Jamaica. Tangible property is comprised of the physical property made up of the Jamaican land, wood and water, people, public property, historical artifacts, indigenous food, flora and fauna (Scarlett-Lozer; 2012). The intangible property consists of creative Jamaican expressions, music and creative industries. There is also an aspect of Brand Jamaica that is not property, it is simply culture, a vibe, a "Jamaican-ness" that one sees or experiences (Scarlett-Lozer; 2012). On the global market, the term "Brand Jamaica" now carries a distinct image of a unique culture, iconic music and dance, exotic cuisine, art and craft rooted in the island's rich heritage, plus a delightful local language. Scarlett-Lozer defines Brand Jamaica "as an asset, and the value seems to 
be appreciating on a daily basis... this asset is constituted by Usain Bolt; Reggae and Dancehall music; the black, green and gold colours of the national flag; Yohan Blake; Jamaican female sprinters; and 'things Jamaican' on a whole. <...> Jamaica, without a shadow of doubt, already has a very strong brand - probably one of the strongest in the world for the size of the country, its population and its economy."(Scarlett-Lozer; 2012). Anholt states that Jamaica has not significantly benefited from its enormous strength as a brand and advised its government to formally adopt a national branding programme for the country's intellectual property. Anholt's Place Branding Hexagon in Figure 1. indicates that nation branding involves more than a country's products and services, culture and heritage, and people. It requires effective and comprehensive management of the country's brand image to ensure that the image represents the positive aspects that will benefit the nation.

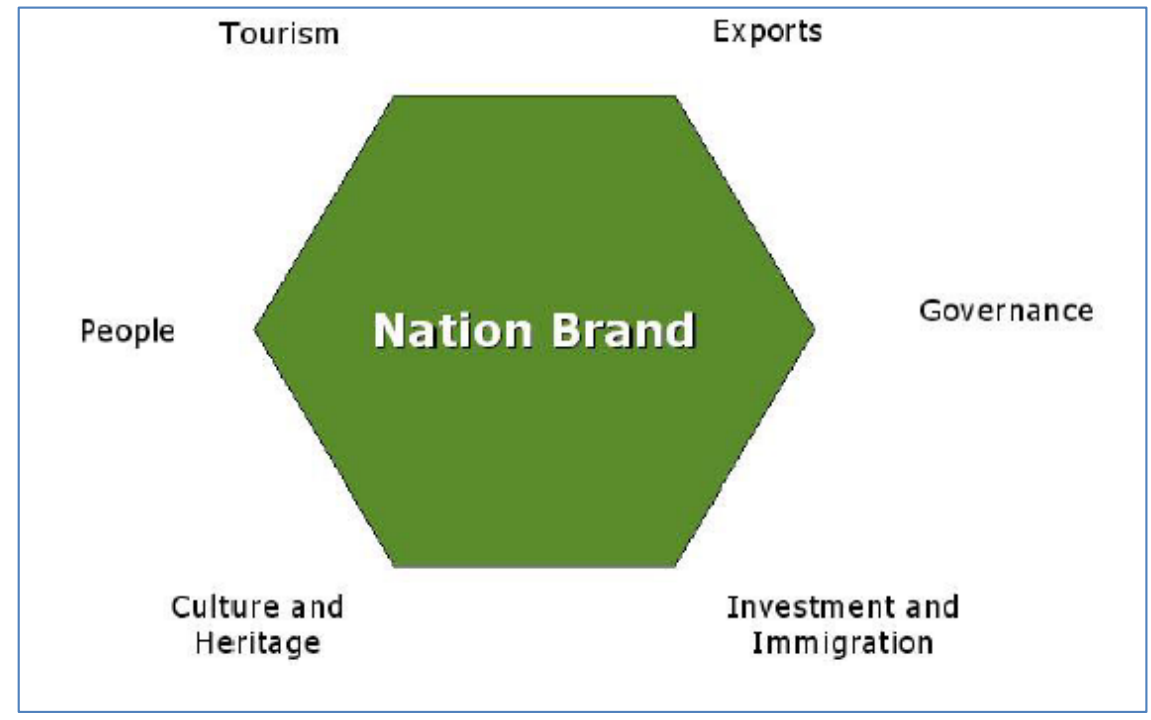

Source: Report by Jamaica to the WIPO Standing Committee on the Law of Trademarks, Industrial Designs and Geographical Indications, p.23

Figure 1. The Place Branding Hexagon

Since Anholt's affirmation of Brand Jamaica's strength, practical steps to define, refine and reposition Brand Jamaica as a business-driven brand, particularly from the perspective of integrating arts, culture, music and sports were developed, with emphasis on making intellectual property protection an integral part of Jamaica's national branding strategy. In 2008, the Jamaican Government formally expressed its intention to develop a national branding strategy since the country had not significantly benefited from its competitive edge as a brand. Likewise, Jamaica is expected to achieve maximum economies of scale from foreign direct investments on IP-based assets, such as tourism and the creative industries. 


\subsection{Brand Jamaica’s intellectual property}

Every country's culture has unique innovative responses to the challenges of each new era. Intellectual property protection provides the vehicle to nurture and promote Brand Jamaica through sports, music or tourism marketing of the brand, which in turn will benefit Jamaica economically and improve the GDP of the country. In the case of Bob Marley, renowned Jamaican musician, he was a cancer patient for more than a year, yet his Rastafarian beliefs precluded him from believing in the reality of death. As such, he did not leave any directions as to the disposition of his estate (King, p. 64; 200). Similarly, if not legally protected, Brand Jamaica can suffer the same demise as the Marley family. It is stated that after Marley's death his family gained millions from licensing fees and patents on his music and recordings, after an expensive and long litigation process to gain rights to his estate. According to his widow, Rita Marley, his royalties accumulated in millions after his death because of his iconic status as an international superstar. "Forbes [Money] magazine estimated Marley's posthumous earnings at \$9 million just between September 2002 and September 2003" (Carrington, p. 65; 2011). Like the Marley family, the Jamaican Government may spend billions of dollars in litigation fees recovering valuable brands affiliated with Jamaica country as Jamaicans and non-Jamaicans alike continue to exploit Brand Jamaica. It is interesting to note that for foreign entrepreneurs wishing to exploit Brand Jamaica, their primary focus is that their consumers think about Jamaica and things Jamaican when making their purchasing decision. It may not be as important that they have Usain Bolt or Yohan Blake in their advertisement. It may only suffice that they have a tall black athletic man photographed or simply a silhouette in full sprint motion or a fusion of reggae music or that they have a red, black, green and gold colour scheme for their business, or Jamaican styled spicy food.

Jamaica, like other Caribbean nations, can achieve maximum economies of scale through IP legislation of its indigenous products. However, the responsibility not only rests on the government, but also on Jamaican entrepreneurs who use the brand, whether for recreational or economic expression. Users of the brand, be it Jamaican musicians, entrepreneurs, or athletes need to claim ownership of the brand, be proactive, register brand indicia, monitor market places, file law suits, send warning letters and negotiate royalty fees (Scarlett-Lozer; 2012). Brand Jamaica can be protected by registering the brand's trademarks, protecting image rights from misappropriation, registering geographical indications, protecting copyright works from infringement, registering patents and industrial designs, and protecting trade. This is necessary as it is the only way Jamaica and Jamaicans can be the true beneficiaries of Brand Jamaica. However, in order to make the benefits of intellectual property available, it is imperative to understand, appreciate, and respect the role that intellectual property protection plays in this regard.

\subsection{Intellectual property protection and Brand Jamaica's creative industries}

Strong intellectual property protection is always desired for brand protection, however there is social cost associated with having this ideal. Aside from the 
bureaucratic costs involved, having strong intellectual property protection can create monopolies and restrict new innovations that are required for the advancement of the society (Report by Jamaica, p. 5-19; 2010). Strong intellectual property protection means that the author or creator in their own right are granted the power to exclude, restrict and control their works created for specific amount of time, which potentially creates monopolistic power. Modern economic analysis supports this assumption (Bush, p.2). Inadvertently, the holder of intellectual property is granted monopoly on the use of the works, however monopoly control only results when the exclusivity of the works is granted for a long durations. To exclude others from making use of the intellectual property results means limited market entry for competitors and less possibilities of market power. At the same time, limited power for short durations can result in less entry barriers in the market and limited market power for the creator. Over the past two decades, economic research suggests that strong intellectual property protection restricts innovation, stagnates creative industries and improvement of current protected intellectual property, since the permission required may be too expensive or may not be granted by the rights holder (Bush, p.5).

In regards to the creative and entertainment services industry it is recognised that this has the greatest potential to promote Brand Jamaica's culture and creativity. According to the report, the music industry already has an estimated rate of 15,000 citizens employed, with an export revenue as high as USD 100 million per annum. Additionally, film location projects around Jamaica are cited for their potential to contribute an additional USD 14 million in the local economy and employment for up to $1,500-2,500$ persons (Report by Jamaica, p.5; 2010). Despite these strengths in creative and entertainment industries, threats such as piracy, copying and adaptations of the Jamaican style and genres by non-Jamaicans is affecting this sector. Instances where non-Jamaicans from other countries have used Jamaican symbols, arts and cultural products, imitating and marketing products Brand Jamaican products that are claimed to originate from Jamaica (geographical indications) and activities that negatively promote Brand Jamaica, have caused potential loss of comparative advantage of the brand in the global market.

In a study conducted in 2007, it was revealed that the economic contribution of the copyright-based industries to Jamaica is quite significant as its contribution amounts to approximately $4.8 \%$ of the total GDP (Report by Jamaica, p.5; 2010). The copyright sector also accounts for $3.03 \%$ of total employment in Jamaica. Within that sector, the percentage of employment is distributed as follows:

- Core copyright industries - $59.3 \%$

- $\quad$ Press and literature - 20\% (of copyright)

- $\quad$ Radio and television - $15.7 \%$

- Music and theatrical productions - 9\%

- Music sector - $6.4 \%$.

However, Jamaica has done significant work towards increasing the value for its creative industries. The results of the study are outlined in Table 1 below: 
Table 1. Economic Contributions from Jamaica's Creative Industries

\begin{tabular}{|l|c|l|}
\hline \multicolumn{1}{|c|}{ INDUSTRY CONTRIBUTOR } & \% TOTAL & \multicolumn{1}{c|}{ AMOUNT } \\
\hline Copyright & $35.6 \%$ & J\$10,363.8 million \\
\hline Radio and television broadcasting & $12.3 \%$ & J\$3578 million (USD 57.3 million) \\
\hline Press and Literature & $10.6 \%$ & J\$3090.8 million ( USD 49.5 million) \\
\hline Music and Theatrical productions & $4.34 \%$ & J\$1263.5 million (USD 20.2 million) \\
\hline Others & $39 \%$ & \multicolumn{1}{|c|}{} \\
\hline Copyright Sector Total (4.8\% of GDP) & & USD 464.7 million \\
\hline
\end{tabular}

Source: Report by Jamaica to the WIPO Standing Committee on the Law of Trademarks Industrial Designs and Geographical Indications, p. 6.

\section{Research of implementing intellectual property protection for Brand Jamaica's creative industries}

\subsection{Methodology}

A systematic analysis of case studies and scientific research journals on country brand literature and its intellectual property was made. The focus was then narrowed to the comparison of Anholt's Nation Brands Index with other nation brand index models. Anholt's Nation Brands Index which is renowned as the leading model on managing and measuring national identity and reputation for a nation, was previously used by the Jamaican Government in a feasibility study for the nation branding of its intellectual property (Report by Jamaica; 2010). From that comparison, it was verified that Anholt's index model is still applicable for representing the strengths of Brand Jamaica, especially in reference to the index parameters, such as Tourism, Exports, Governance, People, Culture and Heritage, and Investment and Immigration.

A research model was developed in order to simplify the relationships between the independent and dependent variables. The independent variable of this research is intellectual property, while the dependent variables are country brands and Brand Jamaica creative industries. From the model there is a relationship between all variables and although the main focus is on Brand Jamaica, it is the creative industries (innovative industries) that require the necessary IP protection to create value for this country brand. Therefore, the hypotheses generated measure the role and relationship of intellectual property for these two dependent variables. As referred above, the hypotheses are:

H1: Trademarks, industrial designs, copyright and other objects of intellectual property protect Brand Jamaica.

H2: Trademarks, industrial designs, copyright and other objects of intellectual property protection create value for Brand Jamaica. 


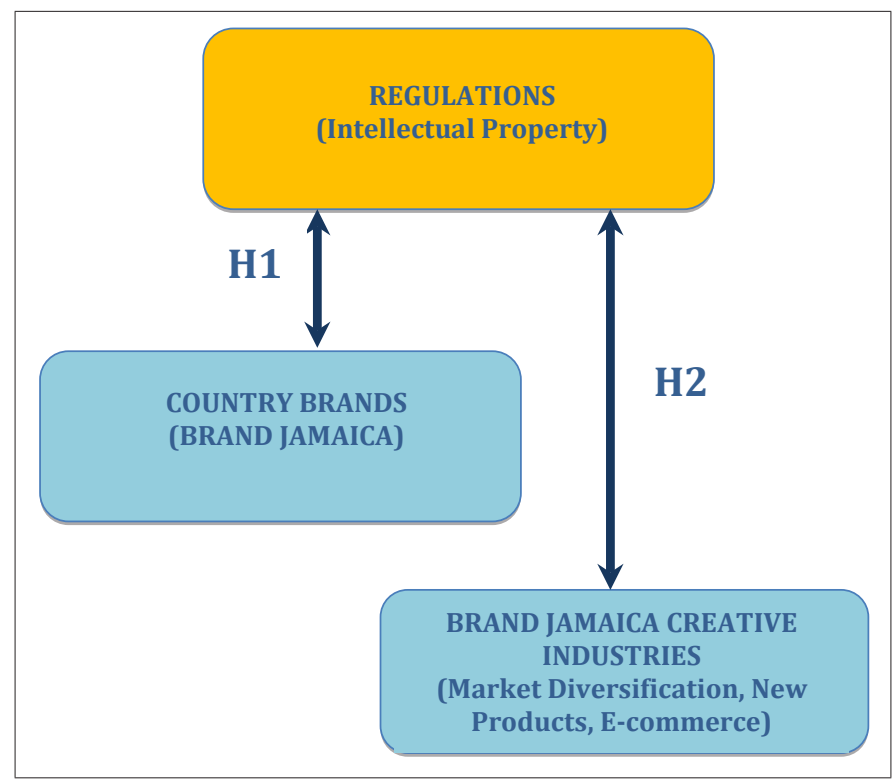

Figure 2. Research Model

The research population was comprised of Jamaicans presently living in the fourteen parishes of Jamaica. Jamaicans were chosen because only the citizens fully understand the meanings and image perceptions associated with Brand Jamaica, and as such are the appropriate research population and sample for the questionnaires. Moreover it is only the citizens who are aware that Brand Jamaica is more than the iconic Bob Marley and reggae music features, or the relaxed casual lifestyle that the tourism brochures advertise; Brand Jamaica also consists of the creative industries sector which is the principal economic feature of the brand - the lesser known yet still important part of Jamaica's economy.

The pilot study carried out involved issuing questionnaires to a sample of 122 Jamaicans. The questionnaires were emailed and distributed manually. From the sample, only 100 Jamaicans responded. The first quarter of the questionnaire focused primarily on the image perceptions of Brand Jamaica; the second quarter was concentrated on the brand's intellectual property and the third quarter on the features of Brand Jamaica's creative industries intellectual property. The remaining quarter focused on the demographic information about the sample. The questionnaires' response sections were structured according to Likert response scale. For the questionnaire response outcomes, the Chi-Square test with a significance level of $5 \%$ will be used to evaluate whether the opinion of Jamaicans supports or rejects the variables of $\mathrm{H} 1$ or $\mathrm{H} 2$.

\subsection{Results and findings}

The questionnaire results were analysed using the numerical analysis and then quantified. The questionnaire responses have revealed that Brand Jamaica requires enforced intellectual property protection. According to the respondents, the elements 
of intellectual property required for protecting Brand Jamaica's creative industries include trademark registration, copyright, geographical indications registrations, patent and industrial property registration. These were further grouped to include "filing more lawsuits for infringement", "protection of trade secrets", and "protecting copyrighted works from infringement". The responses also indicate that Brand Jamaica is exploited at the international level by Jamaicans and Non-Jamaicans alike according to $46 \%$ female respondents, while $61 \%$ of male respondents agreed as well. Most of the respondents agreed that intellectual protection for Brand Jamaica would promote Jamaica's export market, enhance the creative industries of Jamaica, attract investment and international companies to invest more in Jamaica and be beneficial for Jamaican entrepreneurs. However, in order to achieve this, enforced intellectual property protection is required for Brand Jamaica, as this would promote the business use of the brand as well. It is further perceived that the authenticity of locally manufactured goods and services would be preserved and protected both at the local and international level. A majority of the respondents also believe that Brand Jamaica as a business entity in electronic business will do very well for advertising and promotional purposes, with enforced intellectual property protection. As a branded e-commerce web portal, online community/discussion forum, for tourism marketing and social business, most respondents agreed that Brand Jamaica should be used online with enforced intellectual property protection. According to the respondents, not only is intellectual property necessary for protecting the brand, but it also results in higher productivity, since their business will produce more branded Jamaican products that will improve their marketing strategies; branded Jamaican music ensures legal promotion of the Jamaican music industry online and for e-commerce related transactions of that music, as well as preventing the distribution of counterfeit products internationally and locally. According to the responses, Brand Jamaica is an "untapped resource" that is not being utilised to its full potential and the Jamaican Government should do more for developing the brand as well as protecting it. The respondents stated that NonJamaicans are using the brand's name in the business overseas at the expense of the brand. Moreover, it was expressed that enforced IP protection would decrease the level of piracy; improve current international marketing strategies for the brand and create value for the creative industries that includes the country's indigenous reggae music and also create monetary incentives for local artistes. The respondents expressed that since weak protection exists for Brand Jamaica, international media continues to exploit and disrepute the brand's name and redress in terms of lawsuits do not exist for the brand. Given the fact that the internet is slowly gaining momentum and precedence in Jamaica, it is expressed by $50 \%$ female and $37 \%$ male respondents that that electronic business activity, such as e-marketing and e-commerce will promote Brand Jamaica positively on the internet, but not without copyrights and patent registration in place first.

The overall analysis of the responses for the brand management of Brand Jamaica indicates that while the country's brand is already recognised at the local level among the Jamaican citizens, a lot is to be desired for the country's brand, especially in regards to the creative industries sector, which is primarily dominated by the country's indigenous 
reggae music and creative sounds and expressions. From the sample responses it is inferred that this sector requires more development, better management, marketing and distribution of the music. However, enforcing intellectual property to protect national brands by governments in order to create value requires legislation from the Paris Convention, which currently governs jurisdiction regarding the power of states and countries in the field of use of national symbols, emblems and other indigenous commodities. Although 70\% male and 67\% female respondents expressed a desire for the Government of Jamaica to mandate and protect Brand Jamaica's intellectual property, the government cannot protect and manage the use of its country's brand internationally, as that kind recognition and protection must first come from the Paris Convention, then adopted at the local level by its government, then through the Jamaican Intellectual Property Office, JIPO. Although $60 \%$ of respondents agreed that it is the government's responsibility, but the government through JIPO still remains powerless in enforcing stronger intellectual property for Brand Jamaica. Therefore, $\mathrm{H} 1$ is refuted based on the responses and analysis from the questionnaires. Based on the analysis of the findings, there is a direct relationship; country brand's intellectual property requires protection, as it is necessary for creating brand value well.

The assumptions for $\mathrm{H} 2$ states that: "Trademarks, industrial designs, copyrights and other objects of intellectual property protect Brand Jamaica". The percentage finding from the questionnaire reveals that Brand Jamaica can achieve value from enforced intellectual property protection. According to the respondents' answers, it is presumed that intellectual property is actually necessary for creating value for brand Jamaica in the following sectors listed in Table 2.

Table 2. Brand Jamaica economic possibilities through intellectual property rights

\begin{tabular}{|l|c|c|}
\hline \multicolumn{1}{|c|}{ Brand Jamaica Economic Possibilities } & $\begin{array}{c}\text { Female } \\
(\%)\end{array}$ & $\begin{array}{c}\text { Male } \\
(\%)\end{array}$ \\
\hline Attract international companies and / or foreign investments to Jamaica & 50 & 49 \\
\hline Promote the tourism industry more & 21 & 46 \\
\hline Promote public diplomacy and strengthen the brand's image & 42 & 30 \\
\hline Promote the export market & 25 & 52 \\
\hline Revenue & 33 & 49 \\
\hline Protect and promote Reggae music industry & 33 & 30 \\
\hline Increase awareness, personality and equity for the brand & 42 & 37 \\
\hline
\end{tabular}

As can be seen from the table above, intellectual property can create value for Jamaica's key industries. More importantly, over $49 \%$ of respondents believed that by enforcing IP Protection for Brand Jamaica more international companies and foreign investments will increase. Furthermore, the responses also indicate that intellectual property will strengthen Brand Jamaica image globally, promote and protect the Reggae music industry, which can further develop into one of Jamaica's key economic sectors. The findings also indicate that intellectual property can promote the export 
market, which is another key creative industry in Jamaica. Not only will the export and tourism market benefit, but enforced intellectual property will stimulate more brand awareness, personality and equity for Brand Jamaica, which traditionally is a daunting task for country brand managers.

The findings indicate that is there is indeed a direct relationship between country's brand value and intellectual property. Enforced intellectual property creates possibilities for Brand Jamaica in cyberspace especially as a branded e-commerce website portal, as indicated by the respondents. The author strongly supports this, because a branded ecommerce website is ideal for online forums and building brand community and awareness is necessary for improvement of Brand Jamaica. In addition, the branded e-commerce website is also ideal for advertising campaigns of Jamaican brand ambassadors and aspiring personalities from Jamaica, as well as business transactions. Traditional marketing literature confirms that online community forums provide an outlet for customers to connect and interact with the facets of a brand (The Case for Online Communities; 2001); this is also applicable to country brands, especially in tourism and destination sectors that require consumers to recall the brand in order to connect and interact with the country branded personality. Furthermore, a branded e-commerce portal or website ensures the development of brand certification and collective marks on Jamaican products and services in the international market. Empirical research supports that higher value is associated with country branded goods and services that are authentic in nature and not counterfeits. IP protection counters activities, such as piracy and infringements of the intellectual assets of country brands. The findings of the questionnaire confirm that the authenticity of goods and services that are branded and IP protected will achieve revenue for local and online business, ensure higher website protection, decrease illegal piracy and downloading of Brand Jamaican emblems and marks, as well as preserve authenticity. Although some respondents were neutral or did not agree, this may be due to the fact that the e-commerce activity in Jamaica still has online securities regarding transactions made over the internet; there are other studies that confirm this statement, however, e-commerce and electronic business is still emerging in Jamaica and in order for this sector to be successful the role of intellectual property protection is important. The Brand Jamaica concept can be promoted through managing intellectual property as a tradable good or service, supporting authentic Jamaican business enterprises and firms that brand and linked their product or service to the country's national brand. Nation branding strategy is not limited to products alone but also includes significant services, such as the education, creative and entertainment industries. Currently these industries have a strong growth potential and are capable of providing significant foreign exchange earnings for Jamaica. By strengthening this comparative advantage, Jamaica can be a viable education export industry under the Brand Jamaica mark.

Based on the results and findings from the questionnaire, the assumptions for $\mathrm{H} 1$ have been refuted because the findings indicated that trademarks, industrial designs, copyrights and other objects of intellectual property protection were necessary for protecting Brand Jamaica but also to create value for that country brand. From this standpoint, the findings only then prove the assumptions of $\mathrm{H} 2$ which states that: 
"Trademarks, industrial designs, copyrights and other objects of intellectual property create value for Brand Jamaica"

\section{Conclusions}

Brand Jamaica stands to gain overall benefit from an improved infrastructure of intellectual property rights through WIPO. For the Jamaica Intellectual Property Office, JIPO, it continues to advocate for change in the current Paris Convention regarding the right of countries or states to trademark, patent, copyright and controls its national assets through intellectual property laws. The research shows that implementing quality control for intellectual property rights (IPR) that encourages foreign and local investment ensures that Jamaica's current profile converts from a leisure destination to business destination. This is also imperative for developing e-business possibilities and sustaining the creative industries for that brand.

The consequence of enforced intellectual property rights creates more possibilities for Brand Jamaica in cyberspace especially as a branded e-commerce website portal, as indicated by the primary data results. The author strongly agrees with this affirmation, as a branded e-commerce website is ideal for online forums, building brand communities, awareness and feedback from customers, which is necessary for improving the image of Brand Jamaica. Based on the findings from the primary and secondary sources, there is a direct relationship between country brand value and intellectual property for protecting and creating value for Brand Jamaica. Therefore, H1 cannot be accepted.

\section{Literature}

Anderman, S. 2007. The Interface between Intellectual Property Rights and Competition Policy, Cambridge University Press, p. 1-4.

Anholt, S. 2011. Beyond the Nation Brand: The Role of Image and Identity in International Relations (Monograph), Brands and Branding Geographies, Newcastle University, UK, Chapter17.

Baldauf, A., et al. 2003. Performance Consequences of Brand Equity Management: Evidence from Organizations in the Value Chain. Journal of Product \& Brand Management, 12(4): 220-236.

Bush, G.W. 2006. Economic Report of the President, Chapter 10: The Role of Intellectual Property in the Economy.
Carrington, M., and Ogolla, C. 2011. Fame, Family Feuds, Lack of Estate Planning, and Ethical Misconduct in the Administration of the Billion-Dollar Legacy of Bob Marley. Estate Planning \& Community Property Law Journal, 4(1): 53-78

Fan, Y. 2010. Branding the Nation: Towards a Better Understanding, Place Branding and Public Diplomacy 6, 97-103.

Fetscherin, M. 2010. The determinants and measurement of a country brand: the country brand strength index, Type: Research paper, International Marketing Review Volume: 27 Issue: 4.

Grosse, R. 2005. International Business and Government Relations in the 21st 
Century, Cambridge University Press, p. 475-506.

Kapferer, J-N. 2008. The New Strategic Brand Management: Creating and Sustaining Brand Equity Long-term, Fourth Edition.

King, S.A. and Foster, P.R. 2000. No Problem, Mon: Strategies Used to Promote Reggae Music as Jamaica's Cultural Heritage Journal of Nonprofit \& Public Sector Marketing, Vol. 8 (4).

Kotler, P., et al, 2005. Principles of Marketing, Fourth European Edition.

Jamaica Intellectual Property Office Act, 2002.
Report by Jamaica to the WIPO Standing Committee on the Law of Trademarks Industrial Designs and Geographical Indications (SCT), 2010.

Scarlett-Lozer, A. August 12, 2012. Can Brand Jamaica be protected? The Jamaica Observer. [interactive] [accessed on 1509-2013]. <http://www.jamaicaobserver. com/business/Can-Brand-Jamaica-beprotected_12326096\#ixzz2eagdylj>

The Case for Online Communities. Winter 2001. Prepared by McKinsey-Jupiter Media Metrics. 